\title{
Comparison of structural changes in the agriculture and fisheries industries before and after the Great East Japan Earthquake: a case study of Iwate Prefecture's coastal area
}

\author{
Momoka Nakamura $^{1} \cdot$ Toshihiro Hattori $^{2}$ (D) Miku Kariya $^{3}$ \\ Received: 28 August 2021 / Accepted: 2 December 2021 / Published online: 17 January 2022 \\ (c) The Author(s) 2022
}

\begin{abstract}
This study categorised the fishery districts in Iwate Prefecture, which were severely damaged by the Great East Japan Earthquake, using data on agriculture and fishery. Subsequently, changes in the industrial structure of coastal rural areas before and after the earthquake were clarified through an examination of both agriculture and fisheries at the same time. Using cluster analysis, district categories were classified into three cluster types (small-scale primary industry, large-scale primary industry and fishery-dominated clusters) before the earthquake and a fourth cluster (the three aforementioned clusters plus high population density clusters) after the earthquake. The industrial structure's most significant change was in fisherydominated clusters before the earthquake. After the earthquake, clusters with the characteristics of a high population density and small industries emerged. The change in the degree of population decline indicates that the loss of population has not accelerated in the districts where agriculture and fishery have been rebuilt in a balanced manner, although the scale may be either small or large. This finding suggests that both agriculture and fishery are important in coastal rural areas, just as the two were before the earthquake.
\end{abstract}

Keywords Coastal rural areas · Great East Japan Earthquake · Industrial structure · Categorise · Agriculture · Fishery · Comparison

\section{Introduction}

The 2011 Great East Japan Earthquake and Tsunami caused severe damage along eastern Japan's Pacific coast, which has a diverse industrial structure. Reflecting this diversity, the

Toshihiro Hattori

hattori@meiji.ac.jp

Momoka Nakamura

momoka@pa-ss.bb4u.ne.jp

Miku Kariya

ukimayirak@gmail.com

1 Graduate School of Agriculture, Meiji University, 1-1-1

Higashimita, Tama-ku, Kawasaki 214-8571, Japan

2 School of Agriculture, Meiji University, 1-1-1 Higashimita, Tama-ku, Kawasaki 214-8571, Japan

3 Prima Meat Packers, Ltd., Shinagawa Seaside West Tower, 4-12-2 Higashishinagawa, Shinagawa-ku, Tokyo 140-8529, Japan massive disaster's impact also differed, and detailed categorisation of that diversity and its reflection in reconstruction plans might be necessary (Tomita 2014). Furthermore, Tomita's (2014) article states that the diversity of relationships among livelihoods, lifestyles and landforms creates diversity in how we interact with the ocean. Because of diversity's concrete manifestation, consideration of the region's typology is crucial, especially the primary industry as the people's livelihood.

Studies typifying coastal areas have focused on environmental conditions (Cordero et al. 2014; Mahapatra et al. 2015) and ecosystems (Cooper and Jackson 2019; Kaliraj et al. 2019). Others on coastal communities and regional structure include Lee et al. (2006), who classified fishing communities with self-management projects in Korea, and Schumacher et al. (2020), who measured and classified coastal areas' sustainability. Additionally, studies on the regional structure of coastal areas often concern vulnerability (Kumar and Kunte 2012; Murali et al. 2013; Orencio and 
Fujii 2013). Overall, few studies have attempted to categorise coastal areas while also considering primary industries.

As for tsunamis outside Japan, many researchers have studied the damage caused by the 2004 Sumatra-Andaman earthquake. Some study tsunami damage related to the vulnerability of communities and buildings (Koshimura et al. 2009; Leone et al. 2011; Rossetto et al. 2007), and others study the relationship between the tsunami and coastal vegetation (Bayas et al. 2011; Cochard et al. 2008). Focusing on industries and communities are the following studies: the tourism community's vulnerability in Khao Lak, southern Phang Nga Province, Thailand (Calgaro and Lloyd 2008), support for Arugam Bay tourism recovery efforts in Sri Lanka (Robinson and Jarvie 2008), the tsunami in Sri Lanka and southern India (Robinson and Jarvie 2008) and a 4-year study in five tsunami-affected areas of Sri Lanka and southern India (Mulligan et al. 2012).

Several studies related to reconstruction planning and settlement restructuring after the Great East Japan Earthquake have concentrated on affected areas' regional structure, such as Hattori et al. (2018), Kaijima et al. (2017), Morita et al. (2014) and Yamada (2020). Studies focusing on changes before and after the disaster include those on energy (Okushima 2016; Poortinga et al. 2013) and topographical changes (Adityawan et al. 2014; Konagai et al. 2013). As for Iwate Prefecture, studies have addressed tsunami characteristics and damage (Fraser et al. 2013) as well as changes in coastal landforms (Yamashita et al. 2016). Others have addressed damage and recovery in agriculture and rural areas, for instance, Onodera and Kindaichi (2016), Sasaki and Kamata (2012) and Shizukuishi et al. (2012), and on damage and recovery in fisheries and fishing villages, for instance, Goto (2018), (2012), Shizukuishi et al. (2012), Konosu (2013), Sato (2012) and Tamura (2013).

Some further studies have analysed the regional characteristics of fisheries in the Sanriku coastal area (from Iwate to Miyagi prefectures) before and after the earthquake. Ohgaki and Saio (2016) used 20 categories of fishery infrastructure from the fisheries census to categorise 96 fishing districts along the affected coastline in Iwate and Miyagi prefectures according to their actual conditions before and after the earthquake. In districts with many small-scale operators and elderly workers before the earthquake, after the disaster, the number of operators and workers tended to decrease significantly. In contrast, in districts with many operators with high sales value and young workers before the earthquake, afterward many continued to fish even though their sales value decreased; thus, this study discusses continuing fisheries' actual situation. Takano (2013) categorised 77 fishing districts in Iwate and Miyagi prefectures into four main types: (i) a main port fishery town; (ii) a coastal village with self-supportable aquaculture; (iii) a coastal village with aquaculture as a side business; and (iv) a coastal village of partnership management mainly in set-net fishery. Using 23 items from the fisheries census, several studies have categorised fishery districts as knowledge for reconstruction, but no studies have simultaneously considered agriculture and fishery to understand overall industrial structures.

In the coastal rural areas being investigated herein, numerous areas have a small-scale, localised production structure that includes farming and fishing as a livelihood (i.e. part of life) rather than large-scale agriculture and fishing. Many households have traditionally combined both farming and fishing.

Therefore, in the present study, the fishery districts in Iwate Prefecture, which were severely damaged by the Great East Japan Earthquake, are classified using data on agriculture and fishery. The purpose of this study is to identify the changes in the industrial structure of each district and type before and after the earthquake and to examine the various reconstruction methods in coastal rural areas.

\section{Materials and methods}

\section{Survey methods}

After collecting and organising each study area's pre- and post-earthquake data, the data were analysed through principal component analysis, cluster analysis and scatter plots using IBM SPSS software (version 26). The data included 12 items related to population, agriculture and fishery; Table 1 displays the data and sources. For the principal component analysis, the 12 items shown in Table 1 were used to identify the overall characteristics and trends. A cluster analysis was conducted using this data, with the objective of typifying the 26 districts. The hierarchical method was employed, and the Euclidean distance and Ward's method were used to measure the distances. The data were standardised by $\mathrm{Z}$ scores. Scatter plots were created using the principal component scores of components 1 and 2, which were obtained from the principal component analysis, with the aim of providing a visual understanding of the industrial trends in each district.

\section{Study area}

The study area includes 26 of 46 fishing districts in Iwate Prefecture (Fig. 1), excluding those with at least one of the following three conditions: (1) missing data on agriculture (Osawa, Oura, Funakoshi, Kamaishitobu, Hirata, Shirahamaura, Toni and Massaki); (2) a densely inhabited district (DID) (Kuji, Miyako, Kamaishi, Kamaishi-shi-nairiku 
Table 1 Data and sources used

\begin{tabular}{ll}
\hline Data & Source \\
\hline Population increase-decrease rates [\%] & Population Census $(2010,2015)$ \\
Population density [persons $\left./ \mathrm{km}^{2}\right]$ & Population Census $(2010,2015)$ \\
Primary sector of industry rates [\%] & Population Census $(2010,2015)$ \\
Agricultural management entities [entities] $(* 1)$ & Rural communities in Census of Agriculture and Forestry $(2010,2015)$ \\
Size of operating cultivated land [ha] $(* 2)$ & Rural communities in Census of Agriculture and Forestry (2010, 2015) \\
Full-time farmer rates [\%] & Rural communities in Census of Agriculture and Forestry (2010, 2015) \\
Agricultural scale [ha/entities] $(* 2 / * 1)$ & Rural communities in Census of Agriculture and Forestry (2010, 2015) \\
Fishery management entities [entities] $(* 3)$ & Census of Fisheries $(2008,2013)$ \\
Full-time fishery management entities rate [\%] & Census of Fisheries $(2008,2013)$ \\
Fishing boat [boats] $(* 4)$ & Census of Fisheries $(2008,2013)$ \\
Aquaculture rate $[\%]$ & Census of Fisheries $(2008,2013)$ \\
Fishery scale [boats/entities] $(* 4 / * 3)$ & Census of Fisheries $(2008,2013)$ \\
\hline
\end{tabular}

and Ofunato); and/or (3) inland areas not bordering the sea (Kuji-si-nairiku, Tanohata-mura-nairiku, Iwaizumicho-nairiku, Yamada-cho-nairiku, Otsuchi-cho-nairiku, Kamaishi-shi-nairiku, Ofunato-shi-nairiku and Rikuzentakata-shi-nairiku). Kamaishi district falls under both (1) and (2), and it is listed under both. The coastal areas of Iwate Prefecture, which have a small-scale livelihood structure in both agriculture and fisheries and more micromanagement entities than corporate fisheries compared to Miyagi Prefecture, which was also severely damaged by the Great East Japan Earthquake, were selected because they were judged to be appropriate for the purpose of understanding the industrial structure of coastal rural areas. In accordance with the objective of comprehending the industrial structure of these areas, those areas designated as DIDs, which are usually treated as urban areas, were also excluded. DIDs are urban areas that are designated based on statistical data, meet certain criteria and have been designated in each survey since the 1960 Population Census of Japan. DIDs are designated in units of census basic unit blocks and census enumeration districts if there are several census enumeration districts in a census basic unit block (hereinafter 'basic unit blocks, etc.'). In principle, DIDs should meet the following criteria: (1) a district containing basic unit blocks, etc., with a population density of 4000 or more per square kilometre, such districts being adjacent to each other in a municipality and (2) a district comprising the above adjacent basic unit blocks, etc., whose population is 5000 or more at the time of the Population Census of Japan. Based on the idea that DIDs represent urban areas, a basic unit block, etc., which has educational, cultural and recreational facilities (e.g. schools, laboratories, shrines, temples and athletic fields), industrial facilities (e.g. factories, warehouses and business offices) and communal and social welfare facilities (e.g. public offices, hospitals and sanatoria) and is adjacent to the basic unit blocks, etc., mentioned under criterion 1 is also regarded as a district that meets criterion 1. In this regard, however, the population is concentrated in the remaining part, excluding the area occupied by those facilities; alternatively, those facilities occupy more than half the area of the entire district (Statistics Bureau of Japan: https://www.stat.go.jp/english/data/chiri/did/1-1. html Accessed 30 Sept 2021). The Ofunato district, which includes the area of the DID, is a district that possesses a type 3 fishing port (whose scope of use is nationwide) (Fisheries Agency: https://www.jfa.maff.go.jp/j/gyoko_ gyozyo/g_zyoho_bako/gyoko_itiran/sub81.html Accessed 4 Oct 2021) and has a large number of landings; however, because of its strong image of corporate fishing, it was excluded from the target study area Fig. 2.

In terms of the industrial structure of Iwate Prefecture, the prefecture's gross domestic product (GDP) by industry shows that the primary industry accounted for $3.6 \%$, the secondary industry $29.2 \%$ and the tertiary industry $66.6 \%$ in 2017. The primary industry is at a high level compared to the national GDP (the national GDP of the primary industry: $1.2 \%$ ). The value of agricultural production in 2018 totalled 272.7 billion yen, ranking second in Tohoku and tenth in Japan; the number of agricultural enterprises was 46,993 , ranking sixth in Japan. The total number of farmers was 66,099, ranking seventh in Japan, of whom 45,254 were sales farmers, ranking sixth in Japan. Rice, horticulture and livestock farming are flourishing in the prefecture as a whole, with the coastal region being a major producer of strawberries, shiso, beef cattle, pigs, broilers and raw milk. The prefecture has 99 fishing ports and six harbours as well as four type 3 fishing ports (Yamada, Otsuchi, Kamaishi 
Fig. 1 A fishery district of Iwate Prefecture
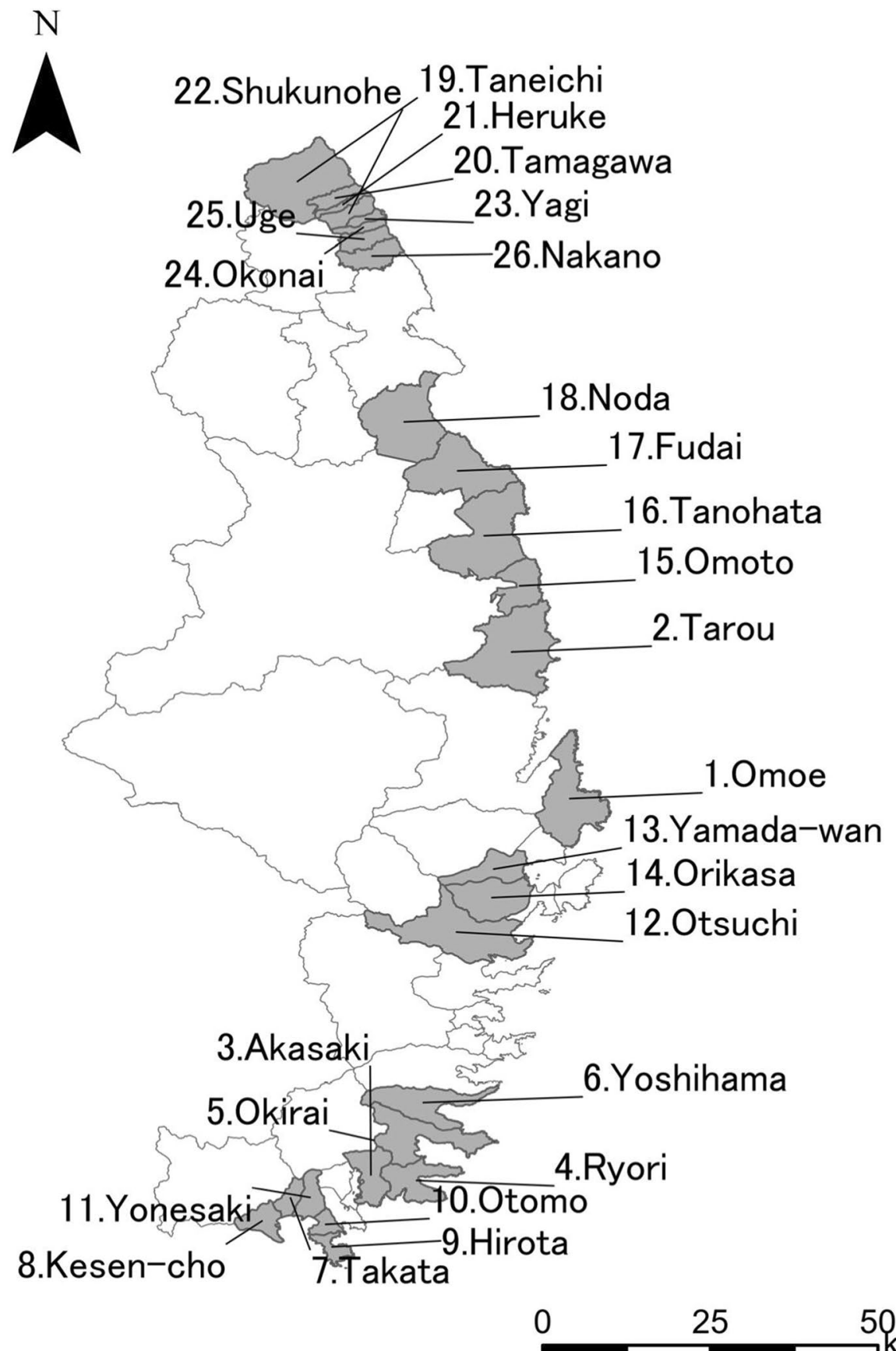

and Ofunato). The number of fishing vessels in 2018 was 5791, ranking fifth in Japan, and the value of marine fisheries and aquaculture was 39.7 billion yen, ranking 12th in Japan. In terms of production, Iwate ranks first in Japan for abalone (marine fisheries) and seaweed (marine aquaculture) and second for salmon (inland water fisheries) (Ministry of Agriculture, Forestry and Fisheries: https://www. maff.go.jp/j/kanbo/tiho/attach/pdf/todouhuken_gaiyou-96. pdf Accessed 4 Oct 2021; Iwate Fisheries Technology Centre: https://www2.suigi.pref.iwate.jp/others/fisheryiwate Accessed 4 Oct 2021).

\section{Results}

\section{Damage caused by the Great East Japan Earthquake and the policy of the prefectural government's reconstruction work}

In Iwate Prefecture's coastal areas, the percentage of farmland damaged among the 12 municipalities was $11.7 \%$. The city of Rikuzentakata had the highest percentage of farmland washed away or flooded at $62.1 \%$, followed by Ofunato at $49.3 \%$. The total amount of damage to agriculture amounted 
to a cost of 58.9 billion yen. Almost all the 111 fishing ports suffered catastrophic damage, with 10,522 fishing vessels devastated. In the aquaculture industry, scallops, oysters, kelp and wakame were severely damaged. The total amount of damage to fisheries and fishing ports amounted to 358.7 billion yen. The reconstruction of industries in Iwate Prefecture has been carried out under the slogan 'Regenerating Industries'. Specifically, in the fisheries industry, support for the bulk purchase of fishing boats and aquaculture facilities, the establishment of a distribution and processing system centred on a fish market in the region, the removal of debris from fishing ports and the restoration and maintenance of facilities have comprised the main focus. By the spring of $2015,97 \%$ of the fishing vessels had been restored, $91 \%$ of the farmland had been restored and $75 \%$ of the affected businesses had resumed operations. Thus, reconstruction has progressed to some extent.

In terms of human damage, Rikuzentakata City (approx. 1800), Otsuchi Town (approx. 1300), Kamaishi City (approx. 1100), Yamada Town (approx. 780), Miyako City (approx. 540) and Ofunato City (approx. 430) had the highest number of victims, in that order. The inundation height was 10-15 $\mathrm{m}$ along the Sanriku coast from the northern part of Iwate Prefecture to the Oshika Peninsula in Miyagi Prefecture to the south. Flooding damage, in which houses were swept away, was extensive in Rikuzentakata City, Ofunato City and Otsuchi Town. The reconstruction of daily life has been carried out under the slogans 'Ensuring Safety' and 'Rebuilding Lives'. Specifically, the early removal of debris, construction of disaster-resistant lifelines, construction of public disaster housing and restoration of medical facilities, public school facilities and public cultural facilities have been carried out. However, the progress in the number of housing lots supplied by the reconstruction projects in the spring of 2015, for example, was $12 \%$, which means that the progress in reconstruction is slower than that of industry (Eto 2012; Iwate Prefecture 2013) (Iwate Prefecture: https:// www.pref.iwate.jp/shinsaifukkou/fukkoukeikaku/keikaku/ 1002586/1002589.html Accessed 4 Oct 2021; Iwate Prefecture: https://www.pref.iwate.jp/_res/projects/default_proje ct/_page_/001/002/302/iwatefukkounoayumi.pdf Accessed 11 Aug 2021; Reconstruction Agency: https://www.recon struction.go.jp/english/topics/Progress_to_date/202009_ Pamphlet_fukkonojokyototorikumi_English.pdf Accessed 11 Aug 2021).

\section{Conditions before the Great East Japan Earthquake}

Table 2 displays the component matrices and contribution rates of principal component analysis before the Great East Japan Earthquake. The data on fisheries are from 2008, and the other data are from 2010. In the component matrix, component 1 shows high values for fishery scale, fishing boats, aquaculture rate and full-time fishery management entities. In component 2 , although values for fishery management entities and full-time fishery management entities are also high, the overall value of items related to agriculture is also high. Therefore, component 1 can be interpreted as 'fishery' and component 2 as 'agriculture'.

Figure 2 shows results of cluster analysis as a dendrogram, cut as indicated by the bold line (around 11) and classified into three clusters: A, B and C. If we cut the data at the point where the distance between clusters is the longest (15-20), we would only have taken out the districts with peculiarities $(20,21,22,23,24,25)$ from the whole. Comparing the data of each district, we can see differences in characteristics between cluster $B(2,12,15,16,17,18,19)$ and cluster C $(1,3,4,5,6,7,8,9,10,11,13,14)$, so it is not appropriate to treat them as one cluster. In addition, cutting at a distance smaller than 11 would create a cluster that consists of only one district. Following a review of the data of 7 (Takata), 9 (Taneichi), etc., it was determined that they were not specific enough to be classified separately in this study. Therefore, we decided on the cut-off points. Seven districts were classified as A: Tamagawa, Heruke, Shukunohe, Yagi, Okonai, Uge and Nakano. Another seven districts were classified as B: Taro, Otsuchi, Omoto, Tanohata, Fudai, Noda and Taneichi. Finally, 12 districts were classified as C: Omoe, Akasaki, Ryori, Okirai, Yoshihama, Takata, Kesen-cho, Hirota, Otomo, Yonesaki, Yamada-wan and Orikasa.

For each cluster, Fig. 3 shows the distribution of districts. Cluster A, a very small district, consists only of districts belonging to Hirono-cho in the north; cluster B, a large district, consists mainly of those north of Miyako and cluster $\mathrm{C}$, a medium district, consists mainly of those in the south of Miyako.

Using the principal component scores obtained from the principal component analysis, a scatter plot was created with component 1 'fishery' on the horizontal axis and component 2 'agriculture' on the vertical axis (Fig. 4). On the horizontal axis, the larger the component score for fishery is to the right, the larger the scale of the fishery industry is; on the vertical axis, the larger component score for agriculture is to the up direction, the larger the scale of the agriculture industry is. Therefore, if we focus on the fishery on the horizontal axis, we can see that the fishery industry is divided into two clusters: cluster A with a small scale of fishery industry and clusters $\mathrm{B}$ and $\mathrm{C}$ with a large scale of fishery industry. If we consider agriculture on the vertical axis, we can see that it is divided into two clusters: $\mathrm{C}$ with a small scale of agriculture industry and $\mathrm{B}$ with a large scale of agriculture industry. Also, cluster A is located at the midpoint between clusters B and C. The scale of agriculture in cluster A can be interpreted as 'intermediate' among the three clusters.

Table 3 summarises the average value of data for each of the three clusters. Although population increase-decrease 
Table 2 Ingredient line and contribution ratio before the 2011 Great East Japan Earthquake
Fig. 2 Cluster analysis before the 2011 Great East Japan Earthquake. The 12 items listed in Table 1 were used. The hierarchical method was used, and Euclidean distance and Ward's method were used to measure the distances. The data were standardised by $\mathrm{Z}$ scores

\begin{tabular}{llllll}
\hline \multicolumn{2}{l}{ Component } \\
\cline { 2 - 6 } & 1 & 2 & 3 & 4 & 5 \\
\hline Population increase-decrease rates [\%] (vs 2005) & -0.030 & -0.527 & 0.247 & 0.527 & 0.423 \\
Population density & 0.111 & -0.563 & 0.572 & 0.261 & -0.419 \\
Primary sector of industry rates [\%] & 0.020 & 0.076 & -0.864 & 0.161 & 0.214 \\
Agricultural management entities (*1) & 0.189 & 0.691 & 0.525 & 0.381 & 0.189 \\
Size of operating cultivated land $(* 2)$ & 0.559 & 0.550 & 0.531 & 0.123 & 0.128 \\
Full-time farmer rates [\%] & -0.172 & 0.395 & 0.323 & -0.596 & 0.370 \\
Agricultural scale [ha] $(* 2 / * 1)$ & 0.605 & -0.115 & 0.256 & -0.438 & -0.404 \\
Fishery management entities $(* 3)$ & 0.605 & 0.503 & -0.275 & 0.309 & -0.343 \\
Full-time fishery management entities rate [\%] & 0.676 & -0.536 & 0.057 & -0.088 & 0.207 \\
Fishing Boat $(* 4)$ & 0.793 & 0.210 & -0.423 & 0.071 & -0.136 \\
Aquaculture rate [\%] & 0.791 & -0.231 & -0.131 & -0.164 & 0.272 \\
Fishery scale $(* 4 / * 3)$ & 0.900 & 0.036 & 0.036 & -0.055 & 0.241 \\
Contribution ratio [\%] & 30.372 & 18.559 & 17.812 & 10.149 & 8.858 \\
Cumulative contribution ratio [\%] & 30.372 & 48.931 & 66.743 & 76.892 & 85.75 \\
\hline
\end{tabular}

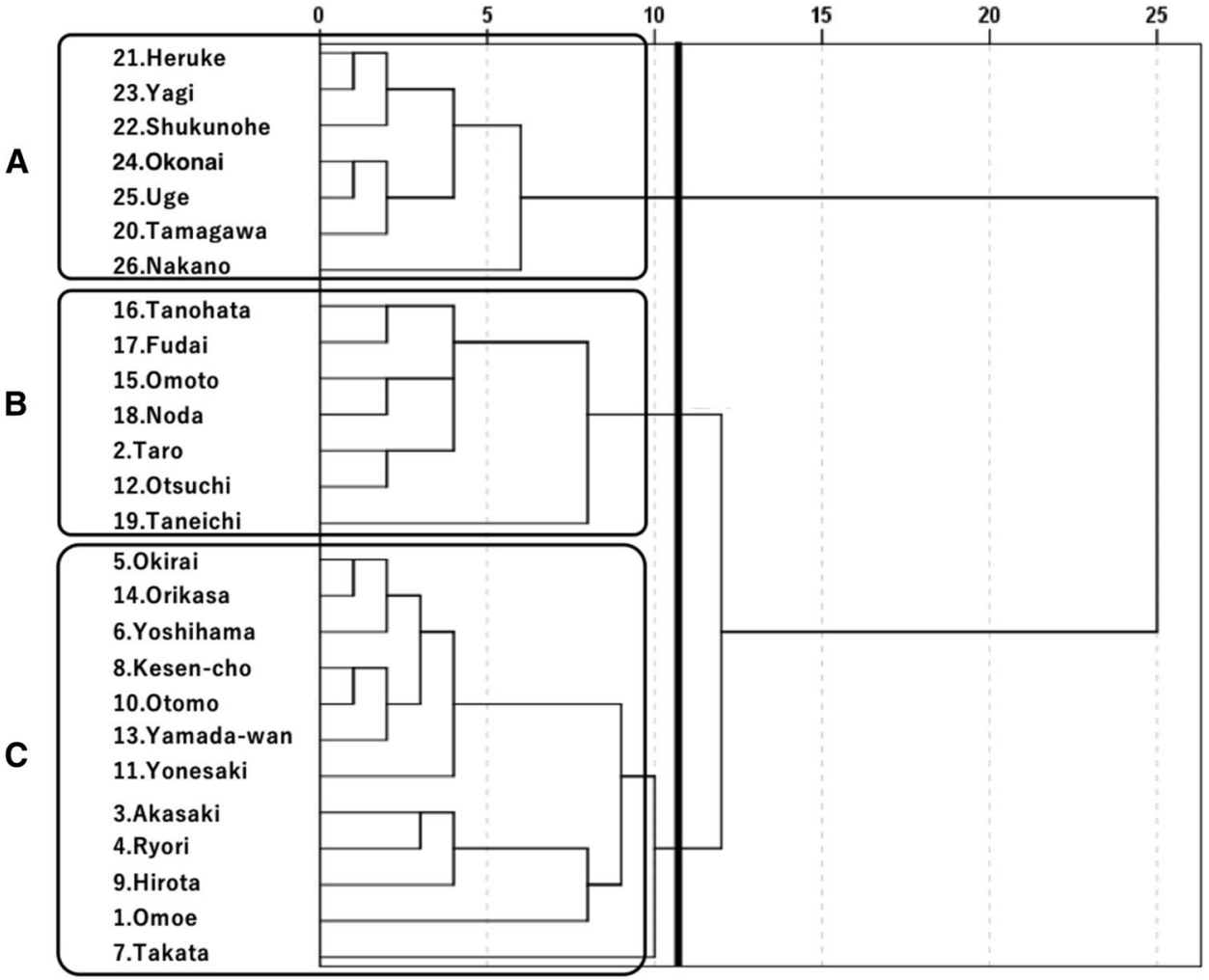

rates do not differ greatly, districts with high population density are clustered in C. Cluster B had very high values of agricultural management entities, size of operating cultivated land, full-time farmer rates, fishery management entities and fishing boats, confirming it as a cluster with both large-scale agriculture and fisheries. In cluster $\mathrm{C}$, items related to agriculture were not outstandingly high, but many related to fishery were slightly higher than in clusters A and
B. In cluster $\mathrm{C}$, fishing prevails over agriculture (fishery excellence), and together with its high population density, this suggests that $\mathrm{C}$ has a strong spatial character as a fishing village without extensive farmland. Meanwhile, cluster A has both small-scale agriculture and fisheries. All seven districts in cluster A belong to Hirono-cho, a long, narrow series of districts in northern Iwate Prefecture running east-west. Since the coastline is short and each district's 
Fig. 3 Cluster locations before the 2011 Great East Japan Earthquake

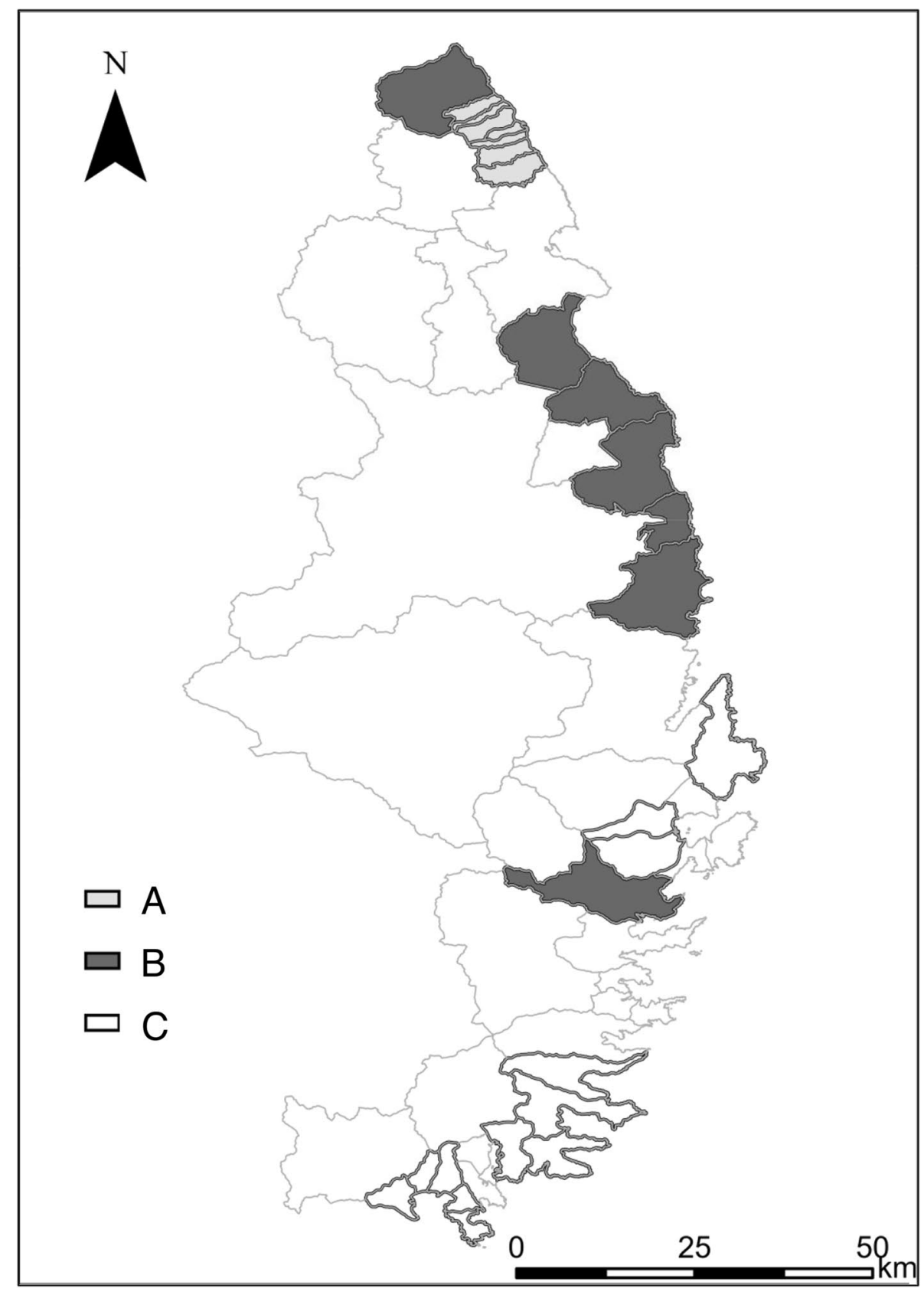

total land area is small, the cluster seems composed only of Hirono-cho, having both small-scale agriculture and fishery. Therefore, cluster A can be considered to have both smallscale agriculture and fishery (small-scale primary industry cluster), cluster B can be considered to have both large-scale agriculture and fishery (large-scale primary industry cluster) and cluster $\mathrm{C}$ can be considered to have active fishery (fishery-dominated cluster).

Table 4 shows each cluster's average number of entities for each fishery type which is practised as an industry: $\mathrm{A}=$ shellfish and seaweed collection; $\mathrm{B}=$ shellfish and seaweed collection and culture in marine water; and $\mathrm{C}=$ mainly culture in marine water. Shellfish and seaweed collection is a main industry and also a side-line or subsistence activity by local residents with fishing rights. In many cases, fishing boats are used for shellfish and seaweed collection as a main occupation, but in side-line and subsistence activities, collection occurs mainly at the waves' edge, and fishing boats are not required.

In cluster A, the district's total land area is small and the coastline short, so the scale of both agriculture and fishery is small. In cluster B, agriculture is large-scale, with many entities engaging in shellfish and seaweed collection, probably because combining farming and shellfish and seaweed 


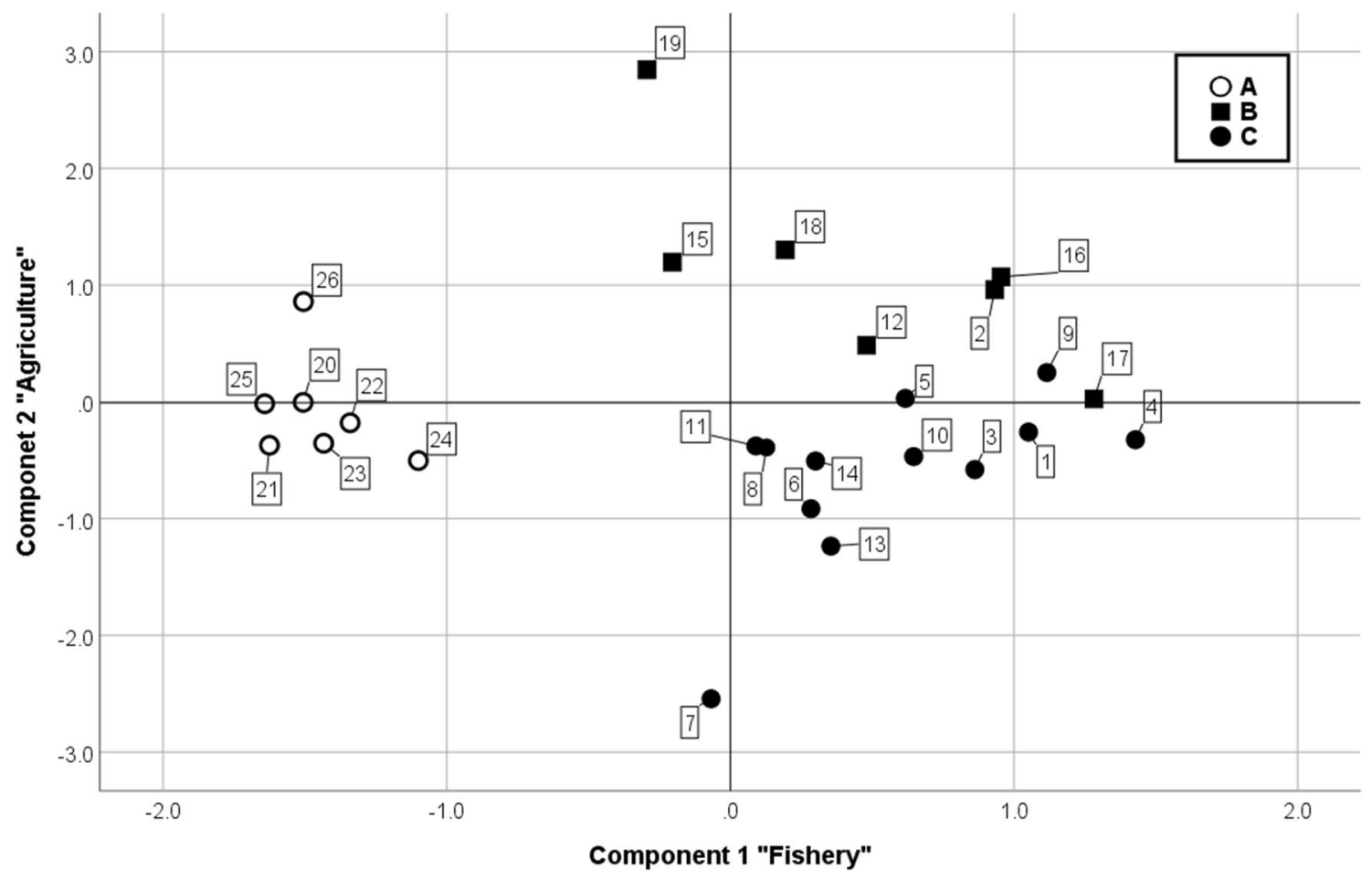

Fig. 4 Scatter plot representing 'before' the 2011 Great East Japan Earthquake

Table 3 Data mean of each cluster's analysis before the 2011 Great East Japan Earthquake

\begin{tabular}{llll}
\hline & A & B & C \\
\hline Population increase-decrease rates [\%] & -7.51 & -8.04 & -6.37 \\
Population density [persons/km ${ }^{2}$ ] & 74.05 & 63.34 & 184.64 \\
Primary sector of industry rates [\%] & 0.25 & 0.20 & 0.22 \\
Agricultural management entities [entities] & 25.71 & 157.00 & 58.00 \\
$\quad(* 1)$ & & & \\
Size of operating cultivated land [ha] $(* 2)$ & 24.87 & 270.33 & 153.58 \\
Full-time farmer rates [\%] & 0.17 & 0.20 & 0.09 \\
Agricultural scale [ha/entities] $(* 2 / * 1)$ & 1.01 & 1.91 & 2.72 \\
Fishery management entities [entities] $(* 3)$ & 47.71 & 185.86 & 126.58 \\
Full-time fishery management entities rate & 0.38 & 0.56 & 0.69 \\
$\quad$ \% ] & & & \\
Fishing boat [boats] $(* 4)$ & 28.57 & 312.14 & 243.08 \\
Aquaculture rate [\%] & 0.00 & 0.32 & 0.60 \\
Fishery scale [boats/entities] $(* 4 / * 3)$ & 0.58 & 1.82 & 1.91
\end{tabular}

collection is relatively easy. In cluster C, the topography of the Rias coast enables many entities to engage mainly in culture in marine water.

\section{Conditions after the Great East Japan Earthquake}

After the Great East Japan Earthquake, principal component analysis was conducted on the data, with Table 5 displaying
Table 4 Each cluster's mean of management bodies for each form of fishing

\begin{tabular}{llll}
\hline & $\mathrm{A}$ & $\mathrm{B}$ & $\mathrm{C}$ \\
\hline Total of fishery management entities [entities] & 334 & 1301 & 1519 \\
Trawl net [entities] & 0.00 & 0.14 & 0.08 \\
Draw net [entities] & 0.00 & 0.71 & 0.67 \\
Gill net [entities] & 3.14 & 11.57 & 7.08 \\
Saury stick-held dip net [entities] & 0.00 & 0.14 & 0.92 \\
Set net [entities] & 0.71 & 4.43 & 2.33 \\
Other net [entities] & 0.00 & 2.14 & 3.08 \\
Long line [entities] & 1.29 & 4.29 & 1.92 \\
Fishing [entities] & 1.57 & 4.14 & 2.50 \\
Diving fisheries [entities] & 0.14 & 0.00 & 0.00 \\
Shellfish and seaweed collection [entities] & 21.43 & 84.43 & 26.50 \\
Other fishery [entities] & 19.43 & 18.00 & 4.83 \\
Culture in marine water [entities] & 0.00 & 55.86 & 76.67 \\
\hline
\end{tabular}

component matrices and contribution rates. The data on fisheries are from 2013, and the other data are from 2015. In the matrix, component 1 has high values for fishing boats, aquaculture rate, fishery scale and fishery management entities; component 2 has high values for size of operating cultivated land, agricultural management entities, full-time farmer rates and agricultural scale. Therefore, component 1 can be interpreted as 'fishery' and component 2 as 'agriculture'. 
Table 5 Ingredient line and contribution ratio after the 2011 Great East Japan Earthquake
Fig. 5 Cluster analysis representing 'after' the 2011 Great East Japan Earthquake. The 12 items listed in Table 1 were used. The hierarchical method was used, and Euclidean distance and Ward's method were used to measure the distances. The data were standardised by $\mathrm{Z}$ scores

\begin{tabular}{|c|c|c|c|c|}
\hline & \multicolumn{4}{|c|}{ Component } \\
\hline & 1 & 2 & 3 & 4 \\
\hline Population increase-decrease rates [\%] (vs 2010) & 0.017 & 0.352 & 0.478 & -0.136 \\
\hline Population density [persons $\left./ \mathrm{km}^{2}\right]$ & -0.297 & -0.289 & -0.428 & 0.541 \\
\hline Primary sector of industry rates [\%] & 0.369 & -0.110 & 0.634 & -0.526 \\
\hline Agricultural management entities [entities] $(* 1)$ & 0.016 & 0.798 & -0.445 & -0.234 \\
\hline Size of operating cultivated land [ha] $(* 2)$ & 0.127 & 0.918 & -0.188 & -0.043 \\
\hline Full-time farmer rates [\%] & 0.011 & 0.526 & 0.352 & 0.605 \\
\hline Agricultural scale [ha/entities] $(* 2 / * 1)$ & 0.405 & 0.427 & 0.404 & 0.436 \\
\hline Fishery management entities [entities] $(* 3)$ & 0.693 & 0.108 & -0.408 & -0.372 \\
\hline Full-time fishery management entities rate [\%] & 0.640 & -0.199 & 0.345 & 0.124 \\
\hline Fishing boat [boats] $(* 4)$ & 0.917 & -0.100 & -0.247 & -0.094 \\
\hline Aquaculture rate [\%] & 0.801 & -0.162 & -0.077 & 0.234 \\
\hline Fishery scale [boats/entities] $(* 4 / * 3)$ & 0.760 & -0.112 & -0.205 & 0.343 \\
\hline Contribution ratio $[\%]$ & 27.975 & 18.828 & 14.393 & 12.795 \\
\hline Cumulative contribution ratio [\%] & 27.975 & 46.803 & 61.196 & 73.991 \\
\hline
\end{tabular}

Figure 5 shows the results of the cluster analysis as a dendrogram, cut as indicated by the bold line (around 15) and classified into four clusters: D, E, F and G. As in the pre-disaster analysis, the classification positions were determined by considering the particularities of the data in each district. For example, when cut off at a distance greater than 15, D and E or F and $G$ are treated as the same group, but it is not appropriate to classify each of the two pairs as the same group based on the characteristics of the data. Takata is a cluster that comprises only one district if the distance is smaller than 15 , but we judged that it is not unique enough to be classified in this study. The cut-off points were thus determined for these reasons. Seven districts were classified as cluster D: Yoshihama, Orikasa, Tamagawa, Heruke, Shukunohe, Okonai and Uge. Six districts were classified as cluster E: Takata, Kesencho, Otomo, Yonesaki, Yagi and Nakano. Four districts were classified as cluster F: Omoto, Tanohata, Noda and 
Fig. 6 Cluster locations after the 2011 Great East Japan Earthquake

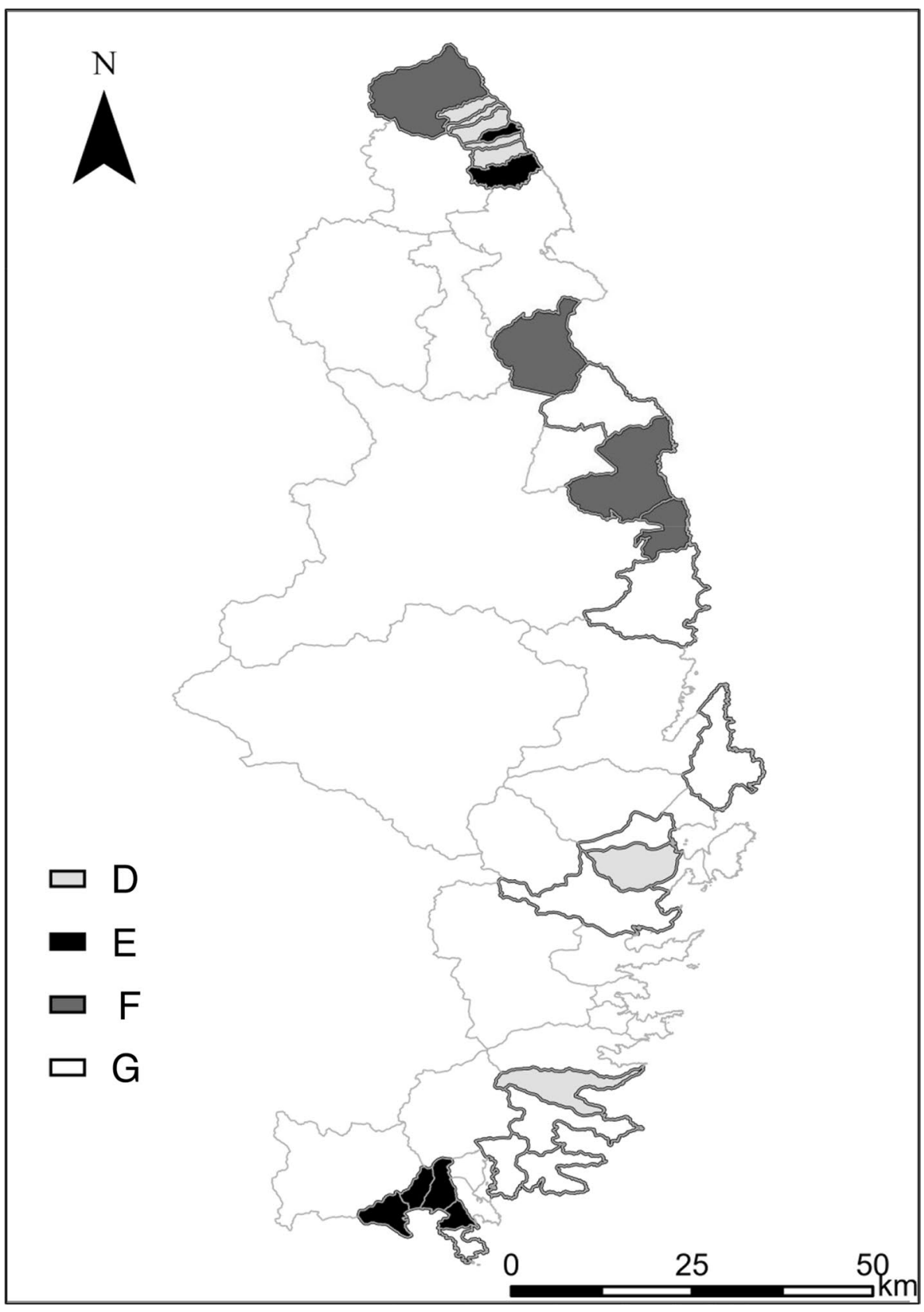

Taneichi. And nine districts were classified as cluster G: Omoe, Taro, Akasaki, Ryori, Okirai, Hirota, Otsuchi, Yamada-wan and Fudai. The distribution of the districts in each cluster is shown in Fig. 6.

As in the analysis in Sect. 3.2, the principal component scores obtained from the principal component analysis were used to create scatter plots for component 1, 'fishery', and component 2, 'agriculture' (Fig. 7). On the horizontal axis, the larger the component score for fishery is to the right, the larger the scale of the fishery industry is; on the vertical axis, the larger the component score for agriculture is to the left, the larger the scale of the agriculture industry is. Therefore, if we focus on fishery on the horizontal axis, we can see that the fishery industry is divided into two clusters: clusters D and $E$ with a small scale and cluster $G$ with a large scale. If we look at agriculture on the vertical axis, we can see that it is divided into two clusters: $D$ and $G$ with a small scale of agriculture industry and $\mathrm{F}$ with a large scale.

Table 6 summarises average values of data for each of the four clusters. In population increase-decrease rates and population density, $\mathrm{E}$ and $\mathrm{G}$ have both the highest rate of decrease and population density. In F, agricultural management entities and size of operating cultivated land are outstandingly high, and fishery management entities and 


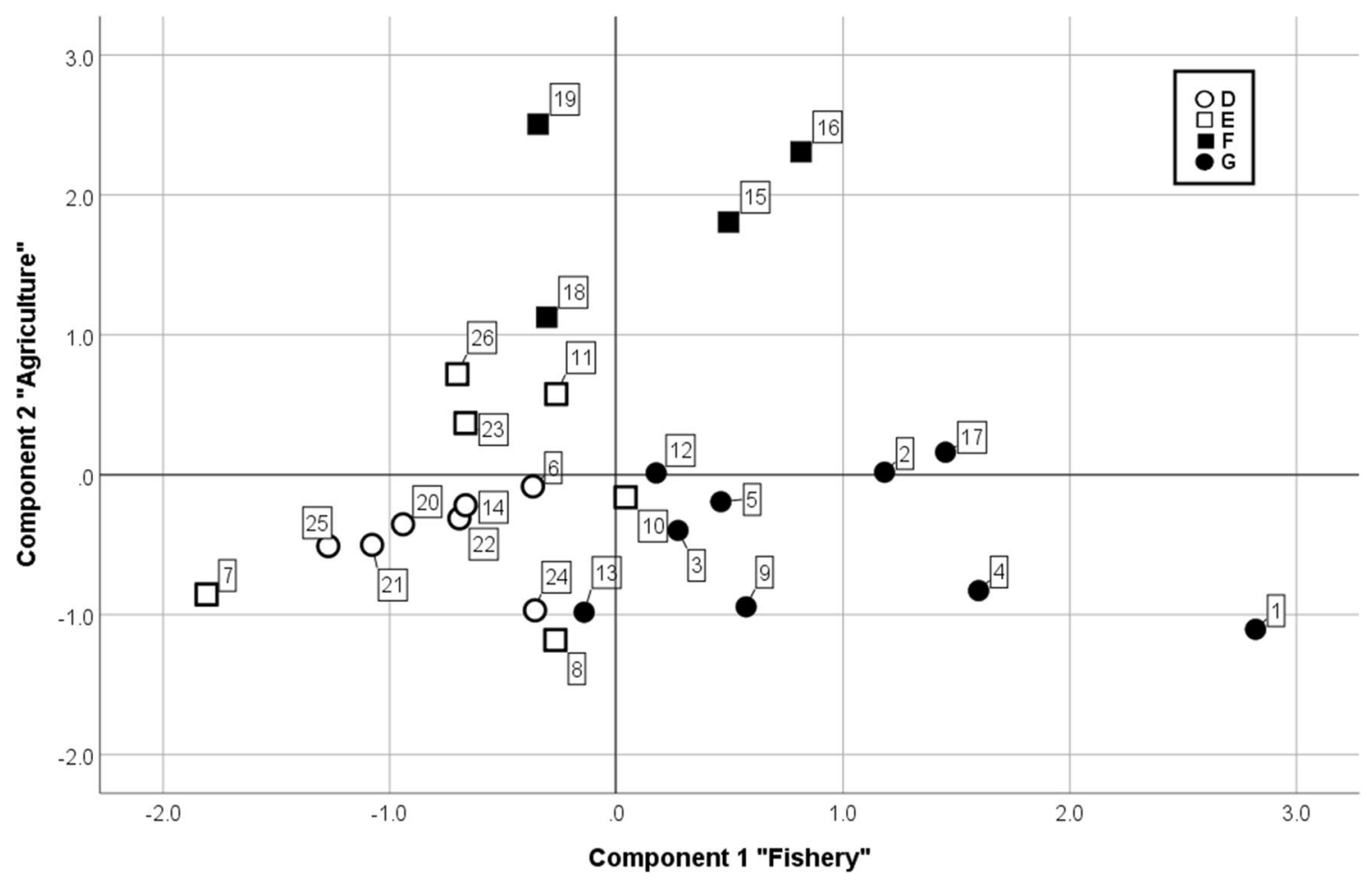

Fig. 7 Scatter plot representing 'after' the 2011 Great East Japan Earthquake

Table 6 Analytical mean of data for each cluster

\begin{tabular}{lllll}
\hline & $\mathrm{D}$ & $\mathrm{E}$ & $\mathrm{F}$ & $\mathrm{G}$ \\
\hline Population increase-decrease rates [\%] & -6.84 & -23.42 & -8.71 & -17.50 \\
Population density [persons/km ${ }^{2}$ ] & 50.15 & 182.82 & 44.41 & 104.84 \\
Primary sector of industry rates [\%] & 0.26 & 0.13 & 0.20 & 0.18 \\
Agricultural management entities [entities] $(* 1)$ & 27.14 & 37.00 & 151.00 & 39.11 \\
Size of operating cultivated land [ha] $(* 2)$ & 21.89 & 50.20 & 275.25 & 42.56 \\
Full-time farmer rates [\%] & 0.09 & 0.23 & 0.21 & 0.13 \\
Agricultural scale [ha/entities] $(* 2 / * 1)$ & 0.76 & 1.82 & 2.08 & 1.37 \\
Fishery management entities [entities] $(* 3)$ & 46.86 & 17.50 & 102.00 & 125.67 \\
Full-time fishery management entities rate [\%] & 0.43 & 0.50 & 0.37 & 0.62 \\
Fishing boat [boats] $(* 4)$ & 42.29 & 24.83 & 137.75 & 273.89 \\
Aquaculture rate [\%] & 0.01 & 0.28 & 0.15 & 0.46 \\
Fishery scale [boats/entities] $(* 4 / * 3)$ & 0.89 & 1.29 & 1.58 & 2.29 \\
\hline
\end{tabular}

fishing boats are also relatively high, indicating a cluster with large-scale agriculture and a large-scale fishery. In G, agricultural items are not as high, but fishery management entities and fishing boats are very high, indicating the cluster is more fishery-centred than agricultural. Cluster D has both small-scale agriculture and a small-scale fishery, although its primary sector of industry rates is high compared with those of others. In E, population density is prominently large, but primary sector of industry rates is the smallest. Both agriculture and fisheries have many items with relatively small values, and they are also urban clusters. Therefore, cluster D can be interpreted as having both small-scale agriculture and fishery (small-scale primary industry cluster), cluster $\mathrm{E}$ as having a considerably large population density (high population density clusters), cluster $\mathrm{F}$ as having both large-scale agriculture and fishery (large-scale primary industry cluster) and cluster $\mathrm{G}$ as active fishery (fishery-dominated cluster).

Table 7 shows each cluster's average number of entities for each fishery type, with shellfish and seaweed collection 
Table 7 Each cluster's mean for management entities of each fishing form

\begin{tabular}{lllll}
\hline & $\mathrm{D}$ & $\mathrm{E}$ & $\mathrm{F}$ & $\mathrm{G}$ \\
\hline $\begin{array}{l}\text { Total of fishery management entities } \\
\quad \text { [entities] }\end{array}$ & 328 & 105 & 408 & 1,131 \\
Trawl net [entities] & 0.00 & 0.00 & 0.00 & 0.00 \\
Draw net [entities] & 0.00 & 0.00 & 1.00 & 2.00 \\
Gill net [entities] & 2.57 & 3.33 & 5.75 & 5.22 \\
Saury stick-held dip net [entities] & 0.00 & 0.00 & 0.00 & 1.00 \\
Set net [entities] & 0.43 & 0.33 & 2.25 & 2.56 \\
Other net [entities] & 0.00 & 0.00 & 3.00 & 4.00 \\
Long line [entities] & 0.00 & 1.00 & 2.00 & 2.00 \\
Fishing [entities] & 0.86 & 0.50 & 1.75 & 2.67 \\
Diving fisheries [entities] & 0.00 & 0.00 & 0.00 & 0.00 \\
Shellfish and seaweed collection [enti- & 29.86 & 3.67 & 55.00 & 32.67 \\
$\quad$ ties] & & & & \\
Other fishery [entities] & 12.86 & 2.17 & 18.25 & 12.56 \\
Culture in marine water [entities] & 0.29 & 6.33 & 13.25 & 61.11 \\
\hline
\end{tabular}

as main activities in D and F, and in G, culture in marine water and shellfish and seaweed collection being the main activities.

\section{Comparison before and after the 2011 Great East Japan Earthquake}

Because industrial characteristics are similar, clusters before and after the earthquake correspond to $\mathrm{A}$ and $\mathrm{D}$ (small-scale primary industry cluster), B and F (large-scale primary industry cluster) and $\mathrm{C}$ and $\mathrm{G}$ (fishery-dominated cluster); after the earthquake, E (high-population-density clusters) newly emerged.

Clusters' changes before and after the earthquake are shown in Table 8 . The largest change in industrial structure occurred in cluster $\mathrm{C}$ (fishery-dominated cluster), where six districts $(50 \%)$ moved their clusters. Two districts moved to D (small-scale primary industry cluster), and four districts moved to $\mathrm{E}$ (high-population-density clusters). Both clusters D and E have small-scale industry; it is likely that the earthquake particularly affected agriculture and fisheries. Cluster B is also highly changed, followed by $\mathrm{C}$. Three districts moved to $\mathrm{G}$.

\section{Changes in cluster $\mathrm{A}$ before and after the earthquake}

Table 9 shows the average values of the main data analysed for the districts belonging to cluster A before the earthquake and the changes in the number of entities by fishery type in each district before and after the earthquake. In terms of population, of the two districts in E, Yagi has a relatively large population density and a large rate of decline after the earthquake, whereas Nakano has a relatively large population density but not a large rate of decline. In terms of agriculture, the five districts in D have a small number of enterprises and a small scale of agriculture, while the two districts in $\mathrm{E}$ have a small number of enterprises but a large scale of agriculture, which has grown even larger since the earthquake. In terms of fisheries, the five districts in D have a small number of operators, but there is not a substantial decrease due to the earthquake, and the fishery is continuing after the earthquake, mainly for shellfish and seaweed

Table 8 Changes in clusters before and after the 2011 Great East Japan Earthquake

\begin{tabular}{|c|c|c|c|c|c|}
\hline & & After & & & \\
\hline & & $\mathrm{D}$ & $\mathrm{E}$ & $\mathrm{F}$ & G \\
\hline & A & 20. Tamagawa & & & \\
\hline & & 21. Heruke & 23. Yagi & & \\
\hline & & 22. Shukunohe & 26. Nakano & & \\
\hline & & 24. Okonai & & & \\
\hline & & 25. Uge & & & \\
\hline \multirow[t]{10}{*}{ Before } & $\overline{\mathrm{B}}$ & & & 15. Omoto & \\
\hline & & & & 16. Tanohata & 2. Taro \\
\hline & & & & 18. Noda & 12. Otsuchi \\
\hline & & & & 19. Taneichi & 17.Fudai \\
\hline & $\mathrm{C}$ & 6.Yosihama & 7. Takata & & 1. Omoe \\
\hline & & 14. Orikasa & 8. Kesen-cho & & 3. Akasaki \\
\hline & & & 10. Otomo & & 4. Ryori \\
\hline & & & 11. Yonesaki & & 5. Okirai \\
\hline & & & & & 9. Hirota \\
\hline & & & & & 13. Yamada-wan \\
\hline
\end{tabular}


Table 9 Average values of main data analysed and changes in number of entities by fishery type $(A \rightarrow D, A \rightarrow E)$

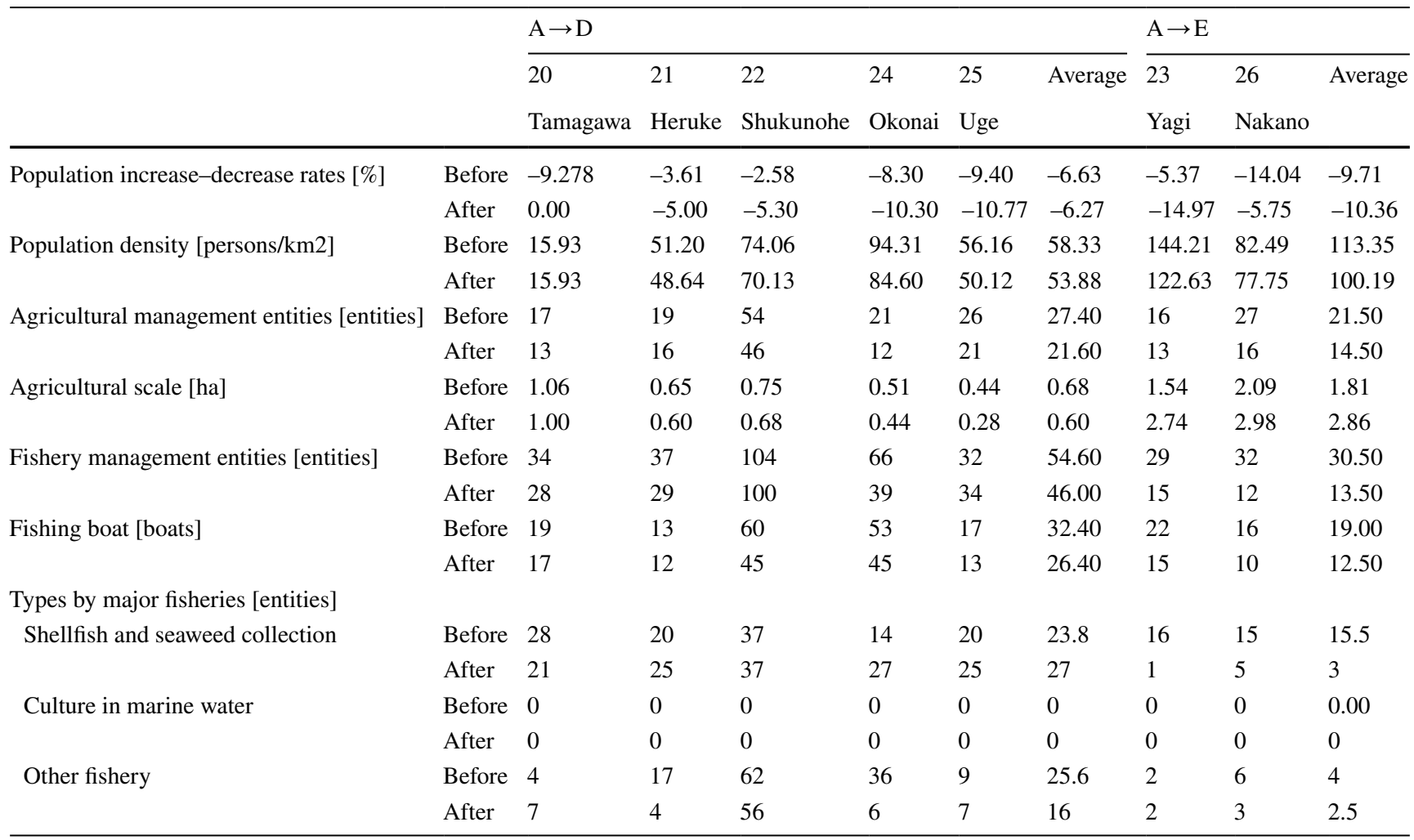

Table 10 Average values of main data analysed and changes in number of entities by fishery type $(B \rightarrow F, B \rightarrow G)$

\begin{tabular}{|c|c|c|c|c|c|c|c|c|c|c|}
\hline & & \multicolumn{5}{|l|}{$\mathrm{B} \rightarrow \mathrm{F}$} & \multicolumn{4}{|l|}{$\mathrm{B} \rightarrow \mathrm{G}$} \\
\hline & & 15 & 16 & 18 & 19 & Average & 2 & 12 & 17 & Average \\
\hline & & Omoto & Tanohata & Noda & Taneichi & & Tarou & Otsuchi & Fudai & \\
\hline \multirow[t]{2}{*}{ Population increase-decrease rates [\%] } & Before & -9.538 & -9.384 & -7.71 & -8.555 & -8.80 & -5.946 & -7.12 & -8.04 & -7.04 \\
\hline & After & -8.046 & -9.81 & -10.427 & -6.557 & -8.71 & -26.266 & -23.608 & -9.488 & -19.79 \\
\hline \multirow[t]{2}{*}{ Population density [persons/km2] } & Before & 36.669 & 24.597 & 56.77 & 75.84 & 48.47 & 42.551 & 162.531 & 44.45 & 83.18 \\
\hline & After & 33.718 & 22.184 & 0.15 & 70.867 & 44.41 & 31.374 & 124.159 & 40.232 & 65.26 \\
\hline \multirow[t]{2}{*}{ Agricultural management entities [entities] } & Before & 120 & 140 & 200 & 328 & 197.00 & 134 & 114 & 63 & 103.67 \\
\hline & After & 99 & 115 & 145 & 245 & 151.00 & 113 & 83 & 48 & 81.33 \\
\hline \multirow[t]{2}{*}{ Agricultural scale [ha] } & Before & 1.808 & 2.55 & 1.78 & 1.125 & 1.82 & 1.708 & 1.622 & 2.841 & 2.06 \\
\hline & After & 2.909 & 3.06 & 1.151 & 1.2 & 2.08 & 0.858 & 1.192 & 1.27 & 1.11 \\
\hline \multirow[t]{2}{*}{ Fishery management entities [entities] } & Before & 130 & 122 & 115 & 311 & 169.50 & 229 & 225 & 169 & 207.67 \\
\hline & After & 53 & 97 & 100 & 158 & 102.00 & 108 & 132 & 145 & 128.33 \\
\hline \multirow[t]{2}{*}{ Fishing boat [boats] } & Before & 219 & 291 & 191 & 132 & 208.25 & 523 & 404 & 425 & 450.67 \\
\hline & After & 122 & 187 & 150 & 92 & 137.75 & 257 & 219 & 353 & 276.33 \\
\hline \multicolumn{11}{|l|}{ Types by major fisheries [entities] } \\
\hline \multirow[t]{2}{*}{ Shellfish and seaweed collection } & Before & 94 & 29 & 51 & 228 & 100.5 & 96 & 82 & 11 & 63.00 \\
\hline & After & 24 & 48 & 47 & 101 & 55 & 31 & 56 & 21 & 36.00 \\
\hline \multirow[t]{2}{*}{ Culture in marine water } & Before & 2 & 9 & 11 & 51 & 18.25 & 16 & 29 & 8 & 17.67 \\
\hline & After & 5 & 6 & 20 & 42 & 18.25 & 6 & 46 & 11 & 21.00 \\
\hline \multirow[t]{2}{*}{ Other fishery } & Before & 13 & 54 & 29 & 2 & 24.5 & 98 & 75 & 120 & 97.64 \\
\hline & After & 6 & 30 & 16 & 1 & 13.25 & 68 & 16 & 85 & 56.33 \\
\hline
\end{tabular}


collection. These results indicate that the districts with large population densities before the earthquake and a significant decrease in the number of fishery management units (especially those focusing on extraction) after the earthquake have moved into the newly created clusters since the earthquake.

\section{Changes in cluster B before and after the earthquake}

Table 10 shows the average values of the main data analysed for the districts belonging to cluster B before the earthquake and the changes in the number of entities by fishery type in each district before and after the earthquake. In terms of population, the areas with relatively high population densities and relatively high rates of population decline after the earthquake have moved to $\mathrm{G}$ (fishery-dominated cluster). In terms of agriculture, three of the four districts in $\mathrm{F}$ have seen an increase in the scale of agriculture, and the remaining one has also seen a small decrease, while two of the three districts in $\mathrm{G}$ have seen a reduction in scale by half. In terms of fisheries, $\mathrm{G}$ has a large number of businesses and fishing vessels and a variety of fishing forms. These results indicate that the three districts from B to $G$ have relatively withdrawn from agriculture owing to reconstruction efforts that are centred on the competitive fishing industry, resulting in a cluster focused on the fishing industry.

\section{Changes in cluster $\mathrm{C}$ before and after the earthquake}

Table 11 shows the average values of the main data analysed for the districts belonging to cluster $\mathrm{C}$ before the earthquake and the changes in the number of entities by fishery type in each district before and after the earthquake. In terms of population, two districts in $\mathrm{D}$ have a small population density and a small rate of decrease; four districts in $\mathrm{E}$ have a substantially large population density and a large rate of decrease after the earthquake. In terms of agriculture, many of the six districts in $G$ have a large rate of decline in the scale of agriculture, while the four districts in $\mathrm{E}$ have a large number of entities among the districts in $\mathrm{C}$. In the case of fisheries, the number of entities in the six districts in $\mathrm{G}$ is considerably large; many of them are mainly engaged in aquaculture rather than extraction, and they have maintained a certain level of scale even since the earthquake. Two districts in D were mainly engaged in aquaculture rather than extraction before the earthquake, but after the earthquake, this reversed, and they are now mainly engaged in extraction. In the four districts of $\mathrm{E}$, the number of entities was small even before the earthquake, but after the earthquake, the number of entities decreased even more significantly.

These results suggest that the two districts in $\mathrm{D}$ became a small cluster owing to the combination of the change in the central fishing pattern and the small population density before the earthquake, and the four districts in E moved to a new cluster after the earthquake because of the large decrease in population density and the number of fishing entities.

\section{Discussion}

The number of districts where there was no structural change $(\mathrm{A} \rightarrow \mathrm{D}, \mathrm{B} \rightarrow \mathrm{F}$ and $\mathrm{C} \rightarrow \mathrm{G})$ is 15 out of 26 districts. Of these, $\mathrm{A} \rightarrow \mathrm{D}$ and $\mathrm{B} \rightarrow \mathrm{F}$ showed no change in population decline before and after the earthquake, whereas $\mathrm{C} \rightarrow \mathrm{G}$ showed an accelerated decline. It is thought that $\mathrm{A} \rightarrow \mathrm{D}$ and $\mathrm{B} \rightarrow \mathrm{F}$ were able to rebuild the stable structure before the earthquake. Conversely, in the case of $\mathrm{C} \rightarrow \mathrm{G}$, although the fishery industry has been rebuilt, there is a problem in rebuilding the residential function (urban area), as shown by the large decrease in population density.

The number of districts with structural changes $(\mathrm{A} \rightarrow \mathrm{E}$, $\mathrm{B} \rightarrow \mathrm{G}, \mathrm{C} \rightarrow \mathrm{D}$ and $\mathrm{C} \rightarrow \mathrm{E}$ ) was 11 out of 26 , of which two districts changed to $\mathrm{D}$, six districts changed to $\mathrm{E}$ and three districts changed to $\mathrm{G}$. In $\mathrm{A} \rightarrow \mathrm{E}$, the recovery of agriculture is progressing, but the recovery of fishery is lagging, and the scale of primary industry is small. In the case of $\mathrm{C} \rightarrow \mathrm{D}$, the scale of the industry is shrinking, but the fishery industry is changing and is converging to a small but stable structure. In the case of $\mathrm{C} \rightarrow \mathrm{E}$, the population density and the number of fishery entities have decreased significantly. These four districts are located in Rikuzentakata City, which was severely damaged by the tsunami, including houses swept away, and it is thought that the collapse of the entire region has affected industrial recovery. In $\mathrm{B} \rightarrow \mathrm{G}$, the reconstruction of agriculture is lagging behind that of fishery; although the cluster has been rebuilt as a fishery-centred cluster, there is a problem in rebuilding the residential function (urban area) owing to the large decrease in population density.

In summary, there are three types of districts: those that have been able to rebuild their pre-earthquake industrial structure $(\mathrm{A} \rightarrow \mathrm{D}$ and $\mathrm{B} \rightarrow \mathrm{F})$, those that have been able to rebuild their industrial structure while changing their industrial composition $(\mathrm{C} \rightarrow \mathrm{D})$ and those that have been able to partially rebuild their primary industries but have yet to rebuild the entire region $(\mathrm{A} \rightarrow \mathrm{E}, \mathrm{C} \rightarrow \mathrm{G}, \mathrm{C} \rightarrow \mathrm{E}$ and $B \rightarrow G$ ). For the primary industry, as mentioned in Sect. 3.1, direct and immediate public support is in place. The fact that reconstruction is progressing with the use of 


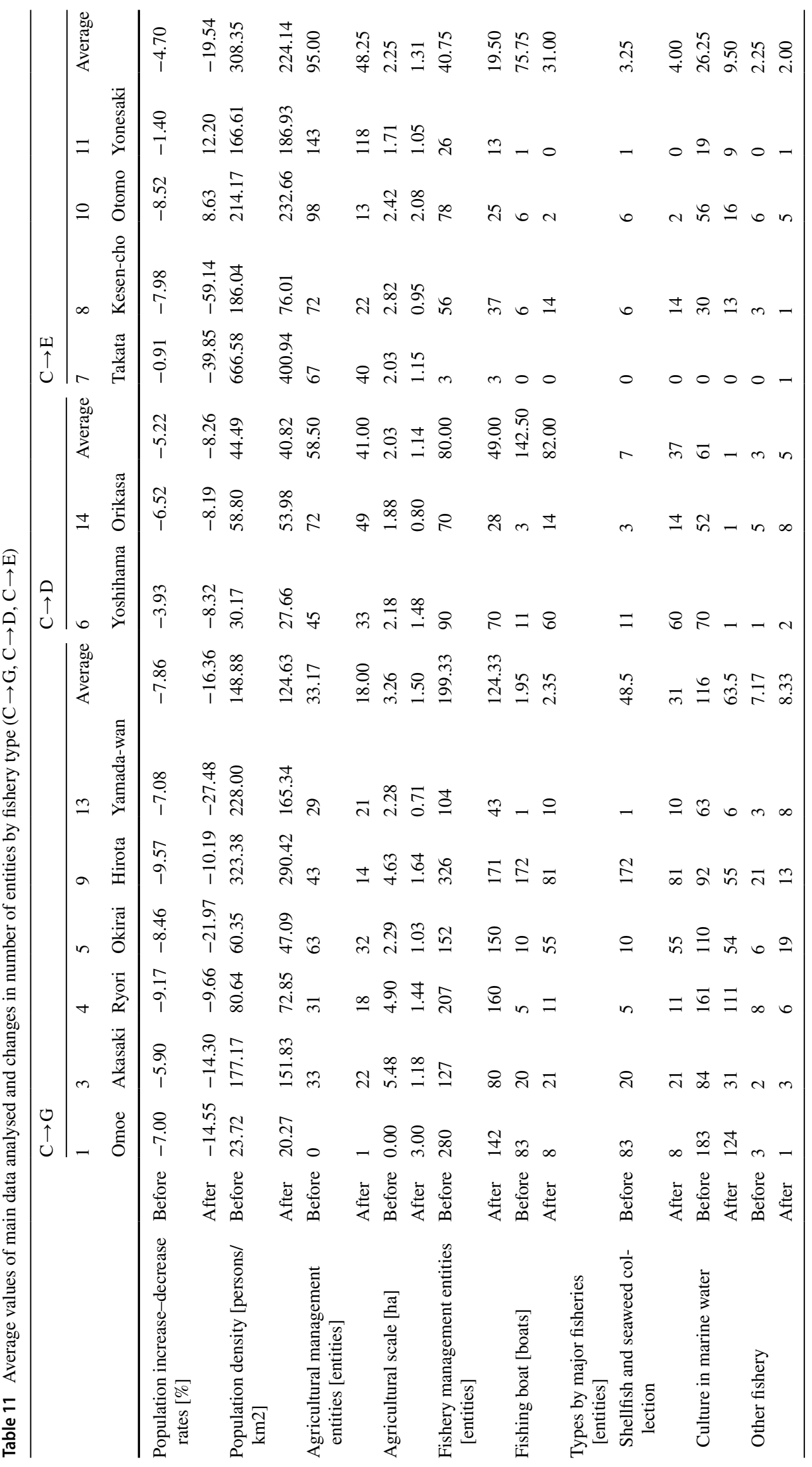


these means of support is thought to have contributed to the relatively low population decline.

In this study, fishery districts in Iwate Prefecture, which were severely damaged by the Great East Japan Earthquake, were classified using both agriculture and fishery data. The changes in the industrial structure of each district, including agriculture and fishery, before and after the earthquake were clarified. While some districts have been able to rebuild their pre-earthquake structures after the earthquake, others are considered to have made little progress in rebuilding some of their industries, as evidenced by the decrease in scale. The change in the degree of population decline indicates that the population decline has not accelerated in the districts wherein agriculture and fishery have been rebuilt in a balanced manner, although the scale may be small or large. This indicates that both agriculture and fishery are important in coastal rural areas, just as they were before the earthquake.

Acknowledgements This work was supported by JSPS KAKENHI [grant numbers 26660193, 16K07948 and 19H03076]. The authors would like to thank Enago (www.enago.jp) for the English language review.

\section{Declarations}

Conflict of Interest There are no conflicts of interest to declare.

Open Access This article is licensed under a Creative Commons Attribution 4.0 International License, which permits use, sharing, adaptation, distribution and reproduction in any medium or format, as long as you give appropriate credit to the original author(s) and the source, provide a link to the Creative Commons licence, and indicate if changes were made. The images or other third party material in this article are included in the article's Creative Commons licence, unless indicated otherwise in a credit line to the material. If material is not included in the article's Creative Commons licence and your intended use is not permitted by statutory regulation or exceeds the permitted use, you will need to obtain permission directly from the copyright holder. To view a copy of this licence, visit http://creativecommons.org/licenses/by/4.0/.

\section{References}

Adityawan MB, Dao NX, Tanaka H, Mano A, Udo K (2014) Morphological changes along the Ishinomaki coast induced by the 2011 Great East Japan Tsunami and the relationship with coastal structures. Coast Eng J 56:1450016

Bayas JCL, Marohn C, Dercon G, Dewi S, Piepho HP, Joshi L, Noordwijk MV, Cadisch G (2011) Influence of coastal vegetation on the 2004 tsunami wave impact in west Aceh. Proc Natl Acad Sci USA 108:18612-18617

Calgaro E, Lloyd K (2008) Sun, sea, sand and tsunami: Examining disaster vulnerability in the tourism community of Khao Lak, Thailand. Singapore J Trop Geogr 29:288-306

Cochard R, Ranamukhaarachchi SL, Shivakoti GP, Shipin OV, Edwards PJ, Seeland KT (2008) The 2004 tsunami in Aceh and Southern Thailand: A review on coastal ecosystems, wave hazards and vulnerability. Perspect Plant Ecol Evol Syst 10:3-40
Cooper JAG, Jackson DWT (2019) Coasts in peril? A shoreline health perspective. Front Earth Sci 7:260

Cordero AS, Quintana MLM, Calvento LH (2014) Reconstructing the environmental conditions of extinct coastal dune systems using historical sources: The case of the Guanarteme dune field (Canary Islands, Spain). J Coast Conserv 18:323-337

Eto H (2012) Statistics and maps observations of municipalities which affected by the Great East Japan Earthquake. Japan Statistical Association (in Japanese)

Fraser S, Raby A, Pomonis A, Goda K, Chian SC, Macabuag J, Offord M, Saito K, Sammonds P (2013) Tsunami damage to coastal defences and buildings in the March 11th $2011 \mathrm{M}(\mathrm{w})$ 9.0 Great East Japan earthquake and tsunami. Bull Earthquake Eng 11:205-239

Goto T (2018) Current status and issues of fishery recovery in Iwate Prefecture. Nippon Suisan Gakkaishi 84:294-297 ((in Japanese))

Hattori T, Shimizu N, Saito A (2018) The regional structure and farming resumption in a tsunami-affected community: The case studies of Otomo and Hirota districts in Rikuzentakata City: Iwate Prefecture. In: Santiago-Fandiño V, Sato S, Maki N, Iuchi K (eds) The 2011 Japan earthquake and tsunami: Reconstruction and restoration insights and assessment after 5 years. Springer, Cham, pp 355-368

Kaijima M, Tsukamoto Y, Sato N (2017) A reorganization method for the living environment in Sanriku village decreasing population by tsunami disaster: Living environment area as network of people, objects and skills. J Hous Res Found Jusoken 43:13-22 ((in Japanese with English abstract))

Kaliraj S, Chandrasekar N, Amachandran KK (2019) Coastal habitat vulnerability of southern India: A multiple parametric approach of GIS based HVI (habitat vulnerability index) model. Geogr Fis Din Quat 42:27-41

Konagai K, Kiyota T, Suyama S, Asakura T, Shibuya K, Eto C (2013) Maps of soil subsidence for Tokyo bay shore areas liquefied in the March 11th, 2011 off the Pacific coast of Tohoku Earthquake. Soil Dyn Earthquake Eng 53:240-253

Konosu T (2013) The significance of fishery reconstruction and cooperatives with fishery cooperatives at the core: From the perspective of the restoration of fisheries and fishing villages and the trend of fishery cooperatives in Iwate. Norinkinyu 2013:368-384 ((in Japanese))

Koshimura S, Oie T, Yanagisawa H, Imamura F (2009) Developing fragility functions for tsunami damage estimation using numerical model and post-tsunami data from Banda Aceh, Indonesia. Coast Eng J 51:243-273

Kumar AA, Kunte PD (2012) Coastal vulnerability assessment for Chennai, east coast of India using geospatial techniques. Nat Hazards 64:853-872

Lee KN, Gates JM, Lee J (2006) Recent developments in Korean fisheries management. Ocean Coast Manag 49:355-366

Leone F, Lavigne F, Paris R, Denain JC, Vinet F (2011) A spatial analysis of the December 26th, 2004 tsunami-induced damages Lessons learned for a better risk assessment integrating buildings' vulnerability. Appl Geogr 31:363-375

Mahapatra M, Ramakrishnan R, Rajawat AS (2015) Coastal vulnerability assessment of Gujarat coast to sea level rise using GIS techniques: A preliminary study. J Coast Conserv 19:241-256

Morita T, Hosokawa Y, Tsukada S, Yuzawa A, Morimoto A (2014) A study on regional structure considering tsunami damage. Sociotechnica 11:1-11 ((in Japanese with English abstract))

Mulligan M, Ahmed I, Shaw J, Mercer D, Nadarajah Y (2012) Lessons for long-term social recovery following the 2004 tsunami: Community, livelihoods, tourism and housing. Environ Hazards-Hum Policy Dimen 1:38-51

Murali RM, Ankita M, Amrita S, Vethamony, (2013) Coastal vulnerability assessment of Puducherry coast, India, using the 
analytical hierarchical process. Nat Hazards Earth Syst Sci 13:3291-3311

Ohgaki K, Saio N (2016) Change of status and issues for reconstruction of fishery villages in the tsunami-affected area of the Great East Japan Earthquake: Relative analysis of fishery situation before and after the earthquake and 'commutation fishing' in Iwate and Miyagi Prefecture. J Rural Plan Assoc 35:167-173 ((in Japanese with English abstract))

Okushima S (2016) Measuring energy poverty in Japan, 2004-2013. Energy Policy 98:557-564

Onodera K, Kindaichi Y (2016) Reconstruction efforts in the coastal area of Iwate after the Great East Japan Earthquake and Tsunami. J Jpn Soc Irrig Drain Rural Eng 80:583-586 ((in Japanese))

Orencio PM, Fujii M (2013) A localized disaster-resilience index to assess coastal communities based on an analytic hierarchy process (AHP). Int J Disaster Risk Reduc 3:62-75

Poortinga W, Aoyagi M, Pidgeon NF (2013) Public perceptions of climate change and energy futures before and after the Fukushima accident: A comparison between Britain and Japan. Energy Policy 62:1204-1211

Iwate Prefecture (2013) Records of the Great East Japan Earthquake and Tsunami in Iwate Prefecture (in Japanese)

Robinson L, Jarvie JK (2008) Post-disaster community tourism recovery: The tsunami and Arugam Bay, Sri Lanka. Disasters 32:631-645

Rossetto T, Peiris N, Pomonis A, Wilkinson SM, Del RD, Koo R, Gallocher S (2007) The Indian Ocean tsunami of 26 December 2004: Observations in Sri Lanka and Thailand. Nat Hazards 42:105-124

Sasaki S, Kamata Y (2012) Investigation and countermeasure for the Great East Japan Earthquake in Iwate Prefecture. J Jpn Soc Irrig Drain Rural Eng 80:257-260 ((in Japanese))

Sato T (2012) The reconstruction problems that became clear from the plans and projects for reconstruction of tsunami stricken fishery village area. J Rural Plan Assoc 31:26-32 ((in Japanese with English abstract))

Schumacher J, Schernewski G, Karnauskaite D, Katarzyte M, Pakleppa S, Pape K, Schonwald S, Volzke M (2020) Measuring and comparing the sustainability of coastal tourism destinations in Germany, Lithuania, and Indonesia. Environ Dev Sustainability 22:2451-2475
Shizukuishi K, Sasaki H, Hirono O (2012) Investigation and countermeasure for the Great East Japan Earthquake in Miyagi Prefecture. J Jpn Soc Irrig Drain Rural Eng 80:261-264 ((in Japanese))

Takano T (2013) On the regional characteristics of fishery in tsunami damaged area in Tohoku and the process to recover. E Journal Geo 8:119-140 ((in Japanese with English abstract))

Tamura N (2013) Current and future state of the fisheries industry in the disaster area. Nippon Suisan Gakkaishi 79:458-462 ((in Japanese))

Tomita H (2014) Understanding of fishing industry and fishing villages, and sustainable structural recovery in the Sanriku region: Revitalizing fisheries use and operations, fishing households' livelihoods, fishing village communities, and marine product industry clusters. Res Environ Disruption 44:33-37 ((in Japanese))

Yamada H (2020) Relationship between the reorganization of affected urban areas and the residential mobility after the Great East Japan Earthquake: Focusing on the affected prefectures of the Tohoku Region, Japan. Q J Geogr 72:71-90 ((in Japanese with English abstract))

Yamashita K, Sugawara D, Takahashi T, Imamura F, Saito Y, Imato Y, Kai T, Uehara H, Kato T, Nakata K, Saka R, Nishikawa A (2016) Numerical simulations of large-scale sediment transport caused by the 2011 Tohoku Earthquake Tsunami in Hirota Bay. Southern Sanriku Coast Coast Eng J 58:1640015

Publisher's Note Springer Nature remains neutral with regard to jurisdictional claims in published maps and institutional affiliations. 